\title{
Comments on the article "high complication rate following dynamic intraligamentary stabilization for primary repair of the anterior cruciate ligament": the story of the cyclops syndrome is not over
}

\author{
Christophe Trojani ${ }^{1}$ (I)
}

Received: 16 January 2019 / Accepted: 29 April 2019 / Published online: 17 June 2019

(c) The Author(s) 2019

\section{Dear Editor-in-Chief,}

I was very interested in reading the article "high complication rate following dynamic intraligamentary stabilization for primary repair of the anterior cruciate ligament" [11]. This article highlights the high rate of complications following primary repair of the anterior cruciate ligament (ACL) by dynamic intraligamentary stabilization (DIS). DIS may lead to healing of an acute ACL rupture [1], especially in case of ACL tear with an intact synovial coverage [2].

Among the described complications, the cyclops syndrome rate is top rank. This syndrome corresponds to a local arthrofibrosis and was described in 1990 as a loss of knee extension after ACL reconstruction due to the progressive development of a fibrovascular nodule at the tibial side of the ACL graft [6]. The term cyclops was chosen because of the eye-like appearance of this lesion on MRI and at arthroscopy, by analogy to the giants of Greek mythology with a single eye in the middle of their forehead. This syndrome includes a progressive loss of knee extension of $10^{\circ}-20^{\circ}$ in the first 6 months after ACL reconstruction, associated with anterior knee pain and a clunk when trying to extend the knee [4].

At the beginning of the twenty-first century, other authors have reported patients presenting a progressive loss of extension after partial or complete ACL tears not treated by surgical reconstruction [9, 14-16]. If associated with a partial ACL tear, the knee is not unstable with a negative pivot shift because of the loss of extension, and patients show an average $10^{\circ}$ loss of extension. During arthroscopy, a cyclops

Christophe Trojani

trojani.c@chu-nice.fr

1 Chirurgie Orthopédique, Unité de Chirurgie du Genou, Institut Universitaire Locomoteur Et du Sport (iULS), Hôpital Pasteur 2, CHU de Nice, 30 Avenue voie Romaine, 06100 Nice, France nodule is easily found when associated with a partial ACL tear, and isolated removal of the cyclops is mandatory. On the contrary, if associated with a complete ACL tear, the cyclops nodule may be hidden in the fat pad. Removal of the cyclops associated with ACL reconstruction is necessary to prevent extension deficit.

More recently, it has been shown that augmentation ACL procedures with preservation of the ACL remnant fibers $[12,13]$ and DIS procedures for primary repair of the ACL $[7,10]$ could lead to a high rate of cyclops syndrome. Augmentation procedures [5] and primary repair [17] are old techniques for ACL tears, and it is well known since more than 30 years, that an augmentation procedure may lead to a mechanical block of extension [5]. One could say that the recent revival of augmentation or primary repair for ACL tears [3, 8], also leads to the revival of well-known complications.

This letter to the editor is therefore intended to recall the potentially high rate of cyclops syndrome encountered with ACL primary repair or augmentation and to alert on the paradox of the cyclops syndrome's recent return, due to the recent revival of old techniques for ACL tears. In conclusion, the story of the cyclops syndrome is not over: it may persist after ACL reconstruction, it is not well known after a partial or complete ACL tear and its revival due to ACL repair, or augmentation techniques is a concern.

Open Access This article is distributed under the terms of the Creative Commons Attribution 4.0 International License (http://creativecommons.org/licenses/by/4.0/), which permits unrestricted use, distribution, and reproduction in any medium, provided you give appropriate credit to the original author(s) and the source, provide a link to the Creative Commons license, and indicate if changes were made.

\section{References}

1. Ahmad SS, Schreiner AJ, Hirschmann MT, Schröter S, Döbele S, Ahrend MD, Stöckle U, Ateschrang A (2019) Dynamic 
intraligamentary stabilization for ACL repair: a systematic review. Knee Surg Sports Traumatol Arthrosc 27(1):13-20

2. Ateschrang A, Schreiner AJ, Ahmad SS, Schröter S, Hirschmann MT, Körner D, Kohl S, Stöckle U, Ahrend MD (2019) Improved results of ACL primary repair in one-part tears with intact synovial coverage. Knee Surg Sports Traumatol Arthrosc 27(1):37-43

3. Colombet P (2018) Editorial commentary: anterior cruciate ligament augmentation: a bold, technically demanding surgical technique... but don't forget to evaluate the benefit-risk ratio. Arthroscopy 34(3):723-725

4. Delincé P, Krallis P, Descamp PY et al (1998) Different aspects of the Cyclops lesion following anterior cruciate ligament reconstruction: a multifactorial pathogenesis. Arthroscopy 14:869-876

5. Fullerton LR, Andrews JR (1984) Mechanical block to extension following augmentation of the anterior cruciate ligament. Am J Sports Med 12:166-168

6. Jackson DW, Schaefer RK (1990) Cyclops syndrome: loss of extension following intraarticular anterior cruciate ligament reconstruction. Arthroscopy 6:171-173

7. Kohl S, Evangelopoulos DS, Schär MO, Bieri K, Müller T, Ahmad SS (2016) Dynamic intraligamentary stabilisation: initial experience with treatment of acute ACL ruptures. Bone Joint J 98-B(6):793-798

8. Mahapatra P, Horriat S, Anand BS (2018) Anterior cruciate ligament repair-past, present, and future. J Exp Orthop 5(1):20

9. Mc Mahon PJ, Bowen MK, Warren RF et al (1999) The cyclops lesion: a cause of diminished knee extension after rupture of the anterior cruciate ligament. Arthroscopy 15:757-761

10. Meister M, Koch J, Amsler F, Arnold MP, Hirschmann MT (2018) ACL suturing using dynamic intraligamentary stabilisation showing good clinical outcome but a high reoperation rate: a retrospective independent study. Knee Surg Sports Traumatol Arthrosc. 26(2):655-659
11. Osti M, El Attal R, Doskar W, Höck P, Smekal V (2019) High complication rate following dynamic intraligamentary stabilization for primary repair of the anterior cruciate ligament. Knee Surg Sports Traumatol Arthrosc 27(1):29-36

12. Sonnery-Cottet B, Lavoie F, Ogassawara R, Scussiato RG, Kidder JF, Chambat P (2010) Selective anteromedial bundle reconstruction in partial ACL tears: a series of 36 patients with mean 24 months follow-up. Knee Surg Sports Traumatol Arthrosc 18(1):47-51

13. Sonnery-Cottet B, Panisset JC, Colombet P, Cucurulo T, Graveleau N, Hulet C, Potel JF, Servien E, Trojani C, Djian P, Pujol N, French Arthroscopy Society (SFA) (2012) Partial ACL reconstruction with preservation of the posterolateral bundle. Orthop Traumatol Surg Res 98(8 Suppl):S165-S170

14. Tonin M, Saciri V, Veselko M, Rotter A (2001) Progressive loss of knee extension after injury: cyclops syndrome due to a lesion of the anterior cruciate ligament. Am J Sports Med 29(5):545-549

15. Trojani C, Coste JS, Michiels JF, Boileau P (2003) Le syndrome du cyclope : un problème déjà présent avant la reconstruction arthroscopique du ligament croisé antérieur. J Trauma Sport 20:76-82

16. Veselko M, Rotter A, Tonin M (2000) Cyclops syndrome occurring after partial rupture of the anterior cruciate ligament not treated by surgical reconstruction. Arthroscopy 16(3):328-331

17. Weaver JK, Derkash RS, Freeman JR, Kirk RE, Oden RR, Matyas J (1985) Primary knee ligament repair-revisited. Clin Orthop Relat Res 199:185-191

Publisher's Note Springer Nature remains neutral with regard to jurisdictional claims in published maps and institutional affiliations. 